\title{
Somogy megye zengólegyeinek katalógusa (Diptera: Syrphidae)
}

\author{
TÓTH SÁNDOR
}

Tórt S.: Checklist of hover-flies of Somogy county (Diptera: Syrphidae)

Abstract: The syrphid fly fauna in Somogy county is better known than most of the syrphid fly fauna in Hungary. According to the data presented by faunistical research programs organized mainly in this area, the hover-fly fauna of the county comprises 226 species, exactly $65 \%$ of the fauna of Hungary. The hover-flies of Duna-Dráva National Park and the Boronka-melléki Landscape Protection Area are especially well known. The fauna is rich in rare and valuable elements such as: Cheilosia lenis (Becker, 1894), Cheilosia schnabli (Becker, 1894), Criorhina ranunculi (Panzer, 1804), Eumerus flavitarsis Zetterstedt, 1843, Eumerus grandis Meigen, 1822, Eumerus ovatus Loew, 1848, Eumerus sabulonum (Fallén, 1817), Orthonevra incisa (Loew, 1843), Pipizella zeneggenensis (Goeldlin de Tiefenau, 1974).

\section{Bevezetés}

Magyarország zengólégy faunájának kutatása viszonylag korán elkezdődött. Ezért Thalhammer Jánosnak, A Magyar Birodalom Állatvilága (Fauna Regni Hungariae) kétszárnyúakat tárgyaló kötete (THALHAMMER 1899) összeállításához, a saját gyüjteménye mellett, viszonylag gazdag faunalisták álltak rendelkezésre. Ezek elsősorban Sopron környékérốl, Zemplén megyéból és Debrecen környékérôl származnak. A gyújtemények sorsáról nem tudunk. Nagy kár, hogy Thalhammernak a Természettudományi Múzeumba került értékes anyaga is megsemmisült 1956-ban, a múzeum csaknem teljes kétszárnyú gyújteményével egyetemben. A múzeum 1956-ban elégett gyújteményének adatait nem publikálták, nagy valószínúséggel voltak benne Somogy megyéból származó zengólegyek is.

Kétségtelen, hogy a Fauna Regni Hungariae nagyon kevés, szám szerint csupán 5 somogyi fajt tartalmaz. Négyet Ốszöd (Balatonôszöd) lelóhelyról: Chrysotoxum lineare (Zetterstedt, 1819), Platycheirus clypeatus (Meigen, I 822), Platycheirus fulviventris (Macquart, 1829), Sphaerophoria rueppelli (Wiedemann, 1830). Egy további fajt (Paragus quadrifasciatus Meigen, 1822) pedig Siófokról.

Ezen kívül a Balaton környén folyó Diptera kutatás eredményeiról készült dolgozat (SzILÁdy 1941) tartalmazza 3 faj somogyi adatát Szemes (Balatonszemes) lelöhelyról: Eristalinus sepulchralis (Linnaeus, 1758), Melanostoma mellinum (Linnaeus, 1758), Heringia virens (Fabricius, 1805), ami alatt nagy valószínüséggel a Pipizella viduata (Linnaeus, 1758) értendó. Szilády a dolgozatában szerepló negyedik fajt (Paragus quadrifasciatus Meigen, 1822) Thalhammer fenti munkájából vette át.

Ezért a faunalista összeállításában, lényegében csak az I 956 utáni gyưjitések, de elsősorban a megye területén szervezett, különbözó tájkutató programok keretében végzett kutatás eredményeképpen rendelkezésre álló adatokra tá- 
maszkodhatunk. Ezeket jelentóségük miatt érdemes külön megemlíteni. A munka a Barcsi Borókás kutatásával kezdődött az 1970-es évek elején, majd késóbb a Zselicben folytatódott. A kutatások elindítása Dr. Uherkovich Ákos múzeumi osztályvezetô (Janus Pannonius Múzeum Természettudományi Osztálya, Pécs), lelkes kutatásszervezô tevékenységének köszönhető. Dr. Ábrahám Levente múzeumi osztályvezetô (Somogy Megyei Múzeum, Természettudományi Osztálya) három éven át (1989-1991) szervezte a létesítés alatt álló Boronka-melléki Tájvédelmi Körzet alapos faunisztikai feltárását. Végezetül az 1990-es évek elején indult a Dráva-mente kutatása, ahol a vizsgálatok már a Duna-Dráva Nemzeti Park megalakulása után fejeződtek be. Ennek a programnak a szervezésében mindkét említett kutató tevékeny szerepet vállalt. A felsorolt programok mindegyikének keretében viszonylagos intenzitással folyt a zengólegyek kutatása. A munka eredményeiból 6 faunisztikai adatközló dolgozat készült (TóTH 1978, 1985, 1992a, 1992b, 1995, 1998), elsősorban ezek adatai képezik az alapját a somogyi faunalista összeállításának.

A zengólegyek a kétszárnyú rovaroknak viszonylag népes családját alkotják. A Földról leírt taxonok száma 5000 fölött van. A Palearktikumból mintegy 1600, Európából kb. 800, Magyarország területéról pedig kereken 350 fajukat tartjuk számon. Bár a hazai fauna viszonylag jól feltárt, a jövőben még leg. alább 20-30 faj kimutatására számíthatunk. A különbözó programoknak köszönhetően, Somogy megye zengólégy faunája különösen jól kutatottnak nevezhető. A rendelkezésre álló adatok alapján, a megye jelenleg ismert zengólégy faunáját 226 faj alkotja, ez a hazai fauna 65\%-át jelenti.

Zengólégy faunánk viszonylag jó feldolgozottsága, lehetôvé teszi az országos gyakorisági értékek öt fokozatban való megadását, az alábbi kategorizálás szerint:

Szórványos előfordulású (I.)

Ritka elófordulású (II.)

Mérsékelten gyakori előfordulású (III.)

Gyakori előfordulású (IV.)

Igen gyakori elöfordulású (V.)

A gyakoriság meghatározása az UTM hálótérképen való előfordulási adatok sajátosságai alapján történik. Az egyes taxonokra jellemző értéket a fajlistában a megfelelő római szám jelzi.

A fauna legérdekesebb, egyben a legértékesebb tagjai, elsósorban a szórványos elófordulású fajok közül kerülnek ki. Ilyen Somogy megyében az alábbi 17 faj:

Brachyopa bicolor (Fallén, 1817)

Brachyopa insensilis Collin, 1939

Cheilosia lenis (Becker, 1894)

Cheilosia schnabli (Becker, 1894)

Criorhina ranunculi (Panzer, 1804)

Eumerus flavitarsis Zetterstedt, 1843

Eumerus grandis Meigen, 1822

Eumerus ovatus Loew, 1848

Eumerus sabulonum (Fallén, 1817)
Eumerus tarsalis Loew, 1848

Ferdinandea ruficornis (Fabricius, 1775)

Orthonevra geniculata (Meigen, 1830)

Orthonevra incisa (Loew, 1843)

Parasyrphus macularis (Zetterstedt, 1843)

Pipizella zeneggenensis (Goeldlin, 1974)

Platycheirus discimanus (Loew, 1871)

Sphacrophoria loewi Zetterstedt, 1843

Ha ehhez hozzávesszük még (de fel nem soroljuk) a 40, ún. ritka elöfordulású (II.) fajt, akkor megállapíthatjuk, hogy a Somogy megyéból ismert zengölegyek kereken egy negyede (25\%), többé-kevésbé ritkának minôsíthetô. 


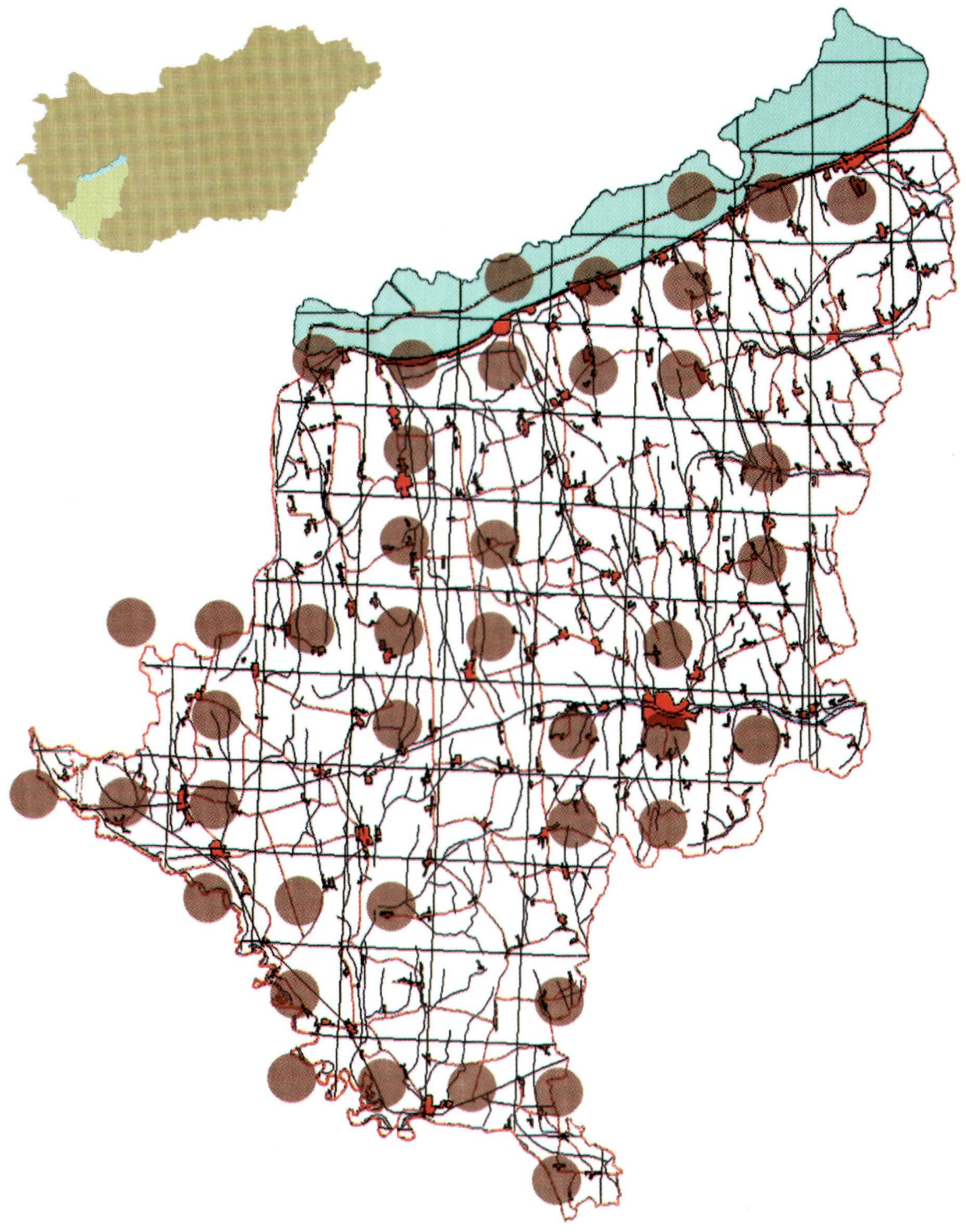

1. ábra: Syrphidae 10x10 km-es UTM mintavételi helyek Somogy megyében 


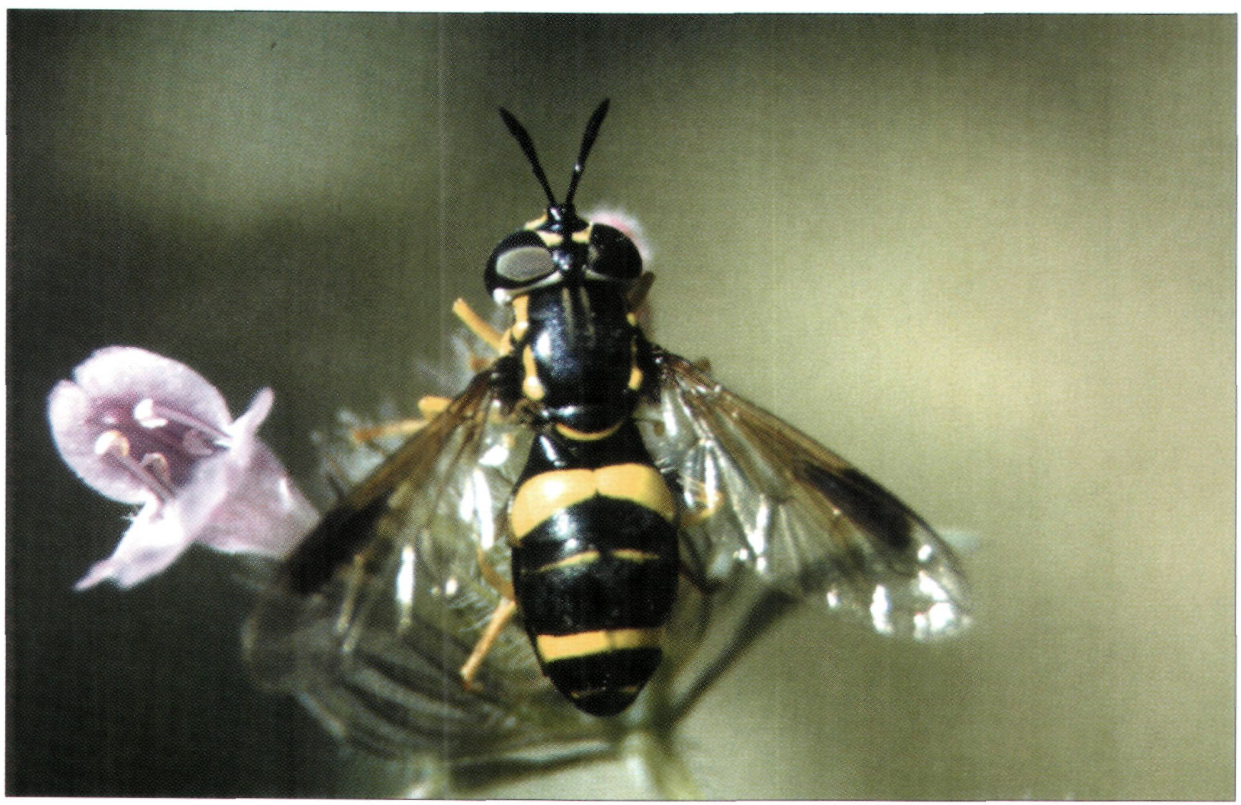

2. ábra: Kétpántos zengólégy (Chrysotoxum bicinctum) Fotó: Tóth S.

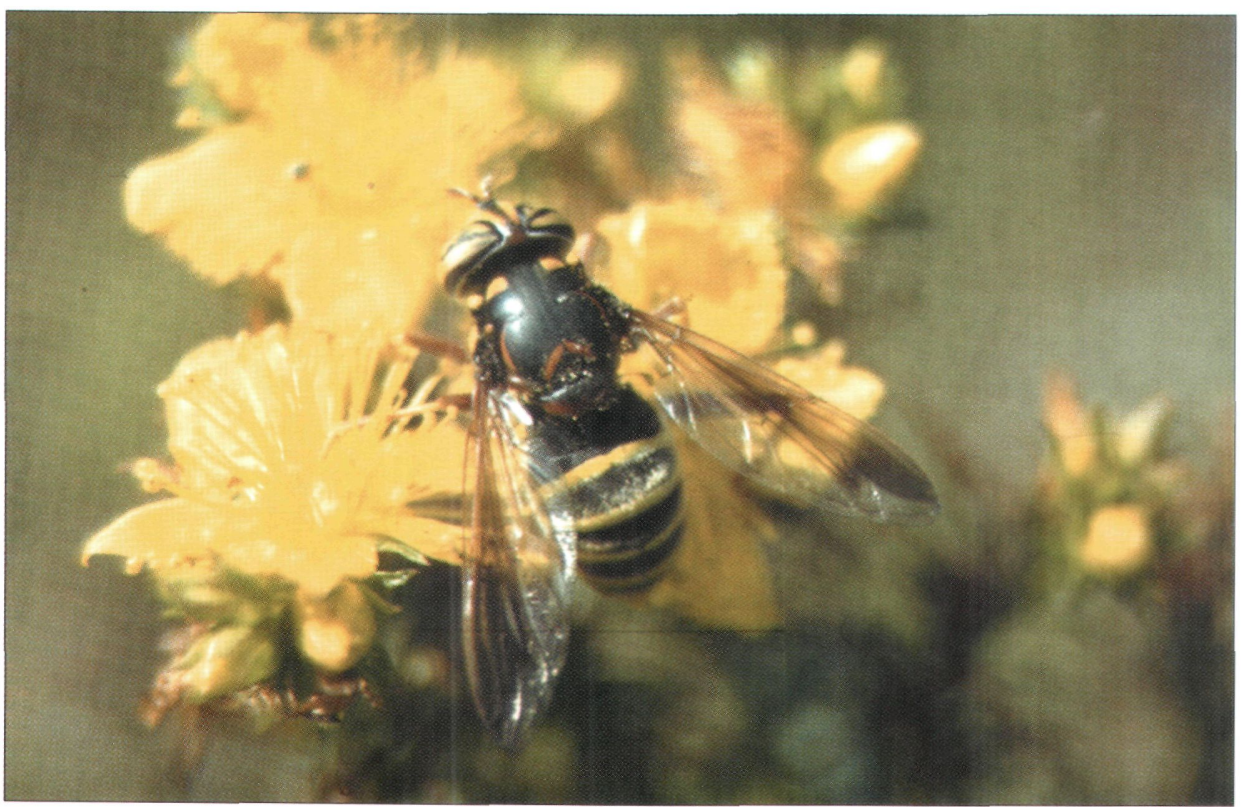

3. ábra: Somogy homokterületeinek ritka zengólegye a Spilomyia diophthalma Fotó: Tóth S. 


\section{A Somogyból ismert fajok jegyzéke}

Anasimyia contracta Claussen \& Torp, 1980 . Tóth 1992b, 1998 (III.)

Anasimyia interpuncta (Harris, 1776) - Tóth 1992b, 1995, 1998 (III.)

Anasimyia lineata (Fabricius, 1787) - Tóth 1978, 1985, 1992b, 1995, 1998 (III.)

Anasimyia transfuga (Linnaeus, 1758) Tóth 1992b, 1995, 1998 (IV.)

Baccha elongata (Fabricius, 1775) - Tóth 1978, 1992a, 1992b, 1995, 1998 (IV.)

Baccha obscuripennis Meigen, 1822 - Tóth 1992a, 1995, 1998 (IV.)

Brachymyia berberina (Fabricius, 1805) Tóth 1992a, 1995, 1998 (II.)

Brachymyia floccosa (Meigen, 1822) - Tóth 1992 a (II.)

Brachyopa bicolor (Fallén, 1817) - Tóth 1998 (I.)

Brachyopa insensilis Collin, 1939 - Tóth 1992 a (I.)

Brachyopa scutellaris Robineau-Desvoidy, 1844 - Tóth 1992b (II.)

Brachypalpoides lentus (Meigen, 1822) -

Tóth 1992b, 1995, 1998 (III.)

Brachypalpus laphriformis (Fallén, 1816) Tóth 1992a, 1995, 1998 (II.)

Brachypalpus valgus (Panzer, 1798) -Tóth 1992a, 1992b, 1995, 1998 (III.)

Caliprobola speciosa (Rossi, 1790) - Tóth 1992a, 1995, 1998 (III.)

Callicera aenea (Fabricius, 1781) - Tóth 1978, 1985, 1992b, 1995, 1998 (II.)

Ceriana conopsoides (Linnaeus, 1758) - Tóth 1992b, 1995, 1998 (III.)

Chalcosyrphus femoratus (Linnaeus, 1758) Tóth 1978, 1985, 1992b, 1998 (II.)

Chalcosyrphus nemorum (Fabricius, 1805) Tóth 1985, 1992a, 1992b, 1995, 1998 (III.)

Cheilosia albipila Meigen, 1838 - Tóth 1992b, 1995, 1998 (III.)

Cheilosia albitarsis (Meigen, 1822) - Tóth 1985, 1992a, 1992b, 1995, 1998 (IV.)

Cheilosia barbata Loew, 1857 - Tóth 1992b, 1995, 1998 (III.)

Cheilosia canicularis (Panzer, 1801) - Tóth 1992 a (III.)

Cheilosia carbonaria Egger, 1860 - Tóth 1992a, 1992b (III.)

Cheilosia chloris (Meigen, 1822) - Tóth $1992 \mathrm{a}, 1992 \mathrm{~b}, 1995,1998$ (III.)

Cheilosia chrysocoma (Meigen, 1822) - Tóth 1992a, 1992b, 1998 (III.)
Cheilosia cynocephala Loew, 1840 - Tóth 1992a, 1992b (III.)

Cheilosia fasciata Schiner \& Egger, 1853 Tóth 1992b (II.)

Cheilosia flavipes (Panzer, 1798). - Tóth 1992a, 1992b, 1995, 1998 (III.)

Cheilosia gigantea (Zetterstedt, 1838) - Tóth $1992 \mathrm{a}, 1992 \mathrm{~b}, 1985,1998$ (III.)

Cheilosia grossa (Fallén, 1817) - Tóth 1992 b, 1998 (III.)

Cheilosia illustrata (Harris, 1780) - Tóth 1992a, 1992b, 1998 (III.)

Cheilosia impressa Loew, 1840 - Tóth 1978, 1985, 1992a, 1992b, 1995, 1998 (IV.)

Cheilosia intonsa Loew, 1857 - Tóth 1992a (III.)

Cheilosia lasiopa Kowarz, 1885 - Tóth 1992b (III.)

Cheilosia laticornis Loew, 1857 - Tóth 1995, 1998 (II.)

Cheilosia lenis (Becker, 1894) - Tóth 1995, 1998 (I.)

Cheilosia mutabilis (Fallén, 1817) - Tóth 1992 a, 1995 (IV.)

Cheilosia nebulosa (Verrall, 1871) - Tóth 1992b, 1995, 1998 (II.)

Cheilosia nigripes (Meigen, 1822) - Tóth 1992a, 1992b, 1998 (III.)

Cheilosia pagana (Meigen, 1822) - Tóth 1992a, 1992b, 1995, 1998 (IV.)

Cheilosia praecox (Zetterstedt, 1843) - Tóth 1985, 1995, 1998 (III.)

Cheilosia proxima (Zetterstedt, 1843) - Tóth 1985, 1998 (III.)

Cheilosia schnabli (Becker, 1894) - Tóth (elókészületben) (I.)

Cheilosia scutellata (Fallén, 1817) - DelyDraskovits 1972, Tóth 1985, 1992a, 1992b, 1995, 1998 (IV.)

Cheilosia soror (Zetterstedt, 1843) - Tóth 1985, 1992a, 1992b, 1995, 1998 (IV.)

Cheilosia variabilis (Panzer, 1798) - Tóth 1978, 1985, 1992a, 1992b, 1995, 1998 (IV.)

Cheilosia velutina Loew, 1840 - Tóth 1992b, 1998 (III.)

Cheilosia vernalis (Fallén, 1817) - Tóth 1992b, 1995, 1998 (III.)

Cheilosia vicina (Zetterstedt, 1849) - Tóth 1992a (III.)

Cheilosia vulpina (Meigen, 1822) - Tóth 1992a (III.)

Chrysogaster cemiteriorum (Linnaeus, 1758) Tóth 1992 b, 1998 (III.) 
Chrysogaster macquarti Loew, 1843 - Tóth 1992 b (II.)

Chrysogaster solstitialis (Fallén, 1817) - Tóth 1985, 1992a, 1992b, 1995, 1998 (IV.)

Chrysotoxum arcuatum (Linnaeus, 1758). Tóth 1978, 1985, 1992a, 1992b, 1995, 1998 (IV.) Chrysotoxum bicinctum (Linnaeus, 1758) Tóth 1978, 1985, 1992a, 1992b, 1995, 1998 (IV.) Chrysotoxum cautum (Harris, 1776) - Tóth 1978, 1985, 1992a, 1995, 1998 (IV.) Chrysotoxum clegans Loew, 1841 - Tóth 1992 b (IV.)

Chrysotoxum lineare (Zetterstedt, 1819). Thalhammer 1899 (II.)

Chrysotoxum vernale Loew, 1841 - Tóth 1978, 1985, 1992a, 1992b, 1995, 1998 (IV.) Chrysotoxum verralli Collin, 1940 - Tóth 1978, 1985, 1992a, 1992b, 1995, 1998 (IV.) Criorhina asilica (Fallén, 1816) - Tóth 1992a, 1992b, 1995, 1998 (III.)

Criorhina ranunculi (Panzer, 1804) - Tóth $1992 \mathrm{a}$ (I.)

Dasysyrphus albostriatus (Fallén, 1817) - Tóth 1978, 1985, 1992a, 1992b, 1995, 1998 (IV.)

Dasysyrphus hilaris (Zetterstedt, 1843) -

Tóth 1978, 1992a (III.)

Dasysyrphus pinastri (De Geer, 1776) - Tóth 1992a, 1992b (III.)

Dasysyrphus tricinctus (Fallén, 1817) - Tóth 1978, 1985, 1992a, 1992b, 1995, 1998 (IV.)

Dasysyrphus venustus (Meigen, 1822) - Tóth 1978, 1985, 1992a, 1992b, 1995, 1998 (IV.)

Didea fasciata Macquart, 1834 - Tóth 1978, 1985, 1992, 1998 (III.)

Didea intermedia Loew, 1854 - Tóth 1978, 1985, 1992, 1998 (III.)

Epistrophe diaphana (Zetterstedt, 1843).

Tóth 1992a, 1995, 1998 (III.)

Epistrophe eligans (Harris, 1780) - Tóth

1978, 1985, 1992a, 1992b, 1995, 1998 (IV.)

Epistrophe flava Doczkal \& Schmid, 1994 -

Tóth 1992a, 1992b, 1995, 1998 (III.) Epistrophe grossulariae (Meigen, 1822).

Tóth 1978, 1985, 1992b, 1995 (III.) Epistrophe melanostoma (Zetterstedt, 1843) -

Tóth 1992a, 1992b, 1995, 1998 (III.) Epistrophe nitidicollis (Meigen, 1822) - Tóth 1978, 1985, I992a, 1992b, 1995, 1998 (IV.) Epistrophe ochrostoma (Zetterstedt, 1849) Tóth 1985, 1998 (II.)

Episyrphus balteatus (De Geer, 1776) - Tóth 1978, 1985, 1992a, 1992b, 1995, 1998 (V.)

Eristalinus aeneus (Scopoli, 1763) - Tóth 1978, 1985, 1992a, 1992b, 1995, 1998 (IV.)
Eristalinus sepulchralis (Linnaeus, 1758) Szilády 1941, Tóth 1978, 1985, 1992b, 1995. 1998 (IV.)

Eristalis abusivus Collin, 1931 - Tóth 1985 (III.)

Eristalis arbustorum (Linnaeus, 1758) - Tóth 1978, 1985, 1992a, 1992b, 1995, 1998 (V.)

Eristalis horticola (De geer, 1976) - Tóth 1978, 1985, 1992a, 1992b, 1995, 1998 (IV.)

Eristalis interrupta (Poda, 1761) - Tóth 1978, 1985, 1992a, 1992b, 1995, 1998 (IV.)

Eristalis intricarius (Linnaeus, 1758) - Tóth 1992b, 1995, 1998 (III.)

Eristalis pertinax (Scopoli, 1763) - Tóth 1978, 1985, 1992a, 1992b, 1995, 1998 (IV.)

Eristalis similis Fallén, 1817 - Tóth 1978, 1985, 1992a, 1998 (III.)

Eristalis rupium (Fabricius, 1805) - Tóth 1992b, 1995, 1998 (III.)

Eristalis tenax (Linnaeus, 1758) - Tóth 1978, 1985, 1992a, 1992b, 1995, 1998 (V.)

Eumerus flavitarsis Zetterstedt, 1843 - Tóth 1998 (I.)

Eumerus grandis Meigen, 1822 - Tóth 1978, 1985,1998 (I.)

Eumerus ornatus Meigen, 1822 - Tóth 1992a, 1992b, 1995, 1998 (III.)

Eumerus ovatus Loew, 1848 - Tóth 1985, 1992 b, 1998 (I.)

Eumerus sabulonum (Fallén, 1817) - Tóth 1985,1998 (I.)

Eumerus sogdianus Stackelberg, 1952 - Tóth 1995, 1998 (IV.)

Eumerus strigatus (Fallén, 1817) - Tóth 1978, 1985, 1992a, 1992b, 1995, 1998 (IV.)

Eumerus tarsalis Loew, 1848 - Tóth 1985, 1998 (I.)

Eumerus tricolor (Fabricius, 1798) - Tóth 1985, 1998 (III.)

Eumerus tuberculatus Rondani, 1857 - Tóth 1995, 1998 (II.)

Eupeodes corollae (Fabricius, 1794) - Tóth 1978, 1985, 1992a, 1992b, 1995, 1998 (V.)

Eupeodes flaviceps (Rondani, 1857) - Tóth 1995 (III.)

Lapposyrphus lapponicus (Zetterstedt, 1838) Tóth 1992b, 1995, 1998 (III.)

Eupeodes latifasciatus (Macquart, 1829) Tóth 1992a, 1992b, 1995, 1998 (IV.)

Eupeodes latilunulatus (Collin, 1931) - Tóth 1992 (II.)

Eupeodes luniger (Meigen, 1822) - Tóth 1978, 1985, 1992a, 1992b, 1995, 1998 (IV.)

Eupeodes nitens (Zetterstedt, 1843) - Tóth 1998 (II.) 
Ferdinandea cuprea (Scopoli, 1763) - Tóth 1978, 1985, 1992a, 1992b, 1995, 1998 (IV.) Ferdinandea ruficornis (Fabricius, 1775) Tóth 1995, 1998 (I.)

Helophilus hybridus Loew, 1846 - Tóth 1978, 1985, 1992b, 1998 (III.)

Helophilus pendulus (Linnaeus, 1758) - Tóth 1978, 1985, 1992a, 1992b, 1995, 1998 (IV.)

Helophilus trivittatus (Fabricius, 1805) - Tóth 1978, 1985, 1992a, 1992b, 1995, 1998 (IV.)

Heringia heringi (Zetterstedt, 1843) - Tóth 1992, 1995, 1998 (III.)

Heringia senilis Sack, 1938 - Tóth 1992a, $1992 b$ (II.)

Lejogaster metallina (Fabricius, 1777) - Tóth 1978, 1985, 1995 (III.)

Lejogaster tarsata (Megerle in Meigen, 1822) - Tóth 1992b, 1995, 1998 (IV.)

Lejops vittata (Meigen, 1822) - Tóth 1995 , 1998 (III.)

Leucozona lucorum (Linnaeus, 1758) - Tóth 1995, 1998 (III.)

Megasyrphus erraticus (Linnaeus, 1758) Tóth I985, 1998 (II.)

Melangyna lasiophthalma (Zetterstedt, 1843) - Tóth 1992b, 1998 (III.)

Melangyna umbellatarum (Fabricius, 1794) Tóth 1998 (III.)

Melanogaster nuda (Macquart, 1829) - Tóth 1992a, 1992b, 1995, 1998 (IV.)

Melanostoma mellinum (Linnaeus, 1758) Szilády 1941, Tóth 1978, 1985, 1992a, 1992b, 1995, 1998 (V.)

Melanostoma scalare (Fabricius, 1794) - Tóth 1978, 1985, 1992a, 1992b, 1995, 1998 (IV.)

Meligramma triangulifera (Zetterstedt, 1843) Tóth 1992b (II.)

Meliscaeva auricollis (Meigen, 1822) - Tóth

1985, 1992a, 1992b, 1995, 1998 (III.)

Meliscaeva cinctella (Zetterstedt, 1843) -

Tóth 1978, 1985, 1992a, 1995, 1998 (III.)

Merodon armipes Rondani, 1843 - Tóth $1992 b, 1995$ (III.)

Merodon avidus (Rossi, 1790) - Tóth 1978, 1985, 1992b, 1995, 1998 (III.)

Merodon constans (Rossi, 1794) - Tóth 1985, 1992a, 1992b, 1995, 1998 (III.)

Merodon equestris (Fabricius, 1794) - Tóth 1992a, 1992b, 1995, 1998 (II.)

Merodon nigritarsis Rondani, 1845 - Tóth 1995, 1998 (III.)

Merodon ruficornis Meigen, 1822 - Tóth 1992b, 1995, 1998 (II.)

Mesembrius peregrinus (Loew, 1846) - Tóth 1978, 1985, 1992a, 1992b, 1995, 1998 (III.)
Microdon devius (Linnaeus, 1761) - Tóth 1992b, 1995, 1998 (III.)

Microdon eggeri Mik, 1897 - Tóth 1992b, 1995, 1998 (III.)

Microdon mutabilis (Linnaeus, 1758) - Tóth 1995, 1998 (III.)

Myathropa florea (Linnaeus, 1758) - Tóth 1978, 1985, 1992a, 1992b, 1995, 1998 (V.)

Myolepta dubia (Fabricius, 1805) - Tóth 1998 (III.)

Myolepta potens (Harris, 1780) - Tóth 1992a, 1992b (II.)

Myolepta vara (Panzer, 1798) - Tóth 1998, 1992a (II.)

Neoascia annexa (Müller, 1776) - Tóth 1985 (III.)

Neoascia interrupta (Meigen, 1822) - Tóth 1985, 1992b, 1995 (III.)

Neoascia meticulosa (Scopoli, 1763) - Tóth 1992a, 1992b, 1995, 1998 (IV.)

Neoascia obliqua Coe, 1940 - Tóth 1992a, 1992b, 1998 (III.)

Neoascia podagrica (Fabricius, 1775) - Tóth 1992, 1995, 1998 (IV.)

Neoascia tenur (Harris, I780) - Tóth 1978, 1985, 1992b, 1995, 1998 (IV.)

Neocnemodon latitarsis (Egger, 1865) - Tóth 1998 (II.)

Neocnemodon vitripennis (Meigen, 1822) Tóth 1995, 1998 (II.)

Orthonevra brevicornis (Loew, 1843) - Tóth 1992b, 1998 (II.)

Orthonevra geniculata (Meigen, 1830) - Tóth $1992 \mathrm{~b}$ (I.)

Orthonevra incisa (Loew, 1843) - Tóth 1992b, 1998 (I.)

Orthonevra intermedia Lundbeck, 1916 Tóth 1992b, 1995, 1998 (II.)

Orthonevra nobilis (Fallén, 1817) - Tóth 1998 (III.)

Orthonevra splendens (Meigen, 1822) - Tóth 1998 (II.)

Paragus allbifrons (Fallén, 1817) - Tóth 1978 (II.)

Paragus bicolor (Fabricius, 1794) - Tóth 1978, 1985, 1998 (III.)

Paragus finitimus Goeldlin de Tiefenau, 1971 - Tóth 1992, 1995, 1998 (III.)

Paragus haemorrhous Meigen, 1822 - Tóth 1985, 1992a, 1992b, 1995, 1998 (IV.)

Paragus majoranae Rondani, 1857 - Tóth 1985, 1992a, 1992b, 1995, 1998 (IV.)

Paragus quadrifasciatus Meigen, 1822 Szilády 1941, Thalhammer 1899 (II.)

Paragus tibialis (Fallén, 1817) - Tóth 1978, 1992b, 1995, 1998 (III.) 
Parasvrphus annulatus (Zetterstedt, 1838) -

Toth 1998 (III.)

Parasyrphus lineola (Zetterstedt, 1843) -

Tóth 1995, 1998 (II.)

Parasyrphus macularis (Zetterstedt, 1843) -

Tóth 1985, 1998 (I.)

Parasprphus punctulatus (Verrall, 1873) -

Tóth 1985, 1992b, 1998 (III.)

Parasyrphus vittiger (Zetterstedt, 1843) -

Tóth 1998 (III.)

Parhelophilus frutetorum (Fabricius, 1775) -

Tóth 1992a, 1992b, 1995, 1998 (III.)

Parhelophilus versicolor (Fabricius, 1794) -

Tóth 1978, 1985, 1992b, 1995, 1998 (IV.)

Pelecocera latifrons Loew, 1856 - Tóth $1992 \mathrm{a}$,

1992b, 1995, 1998 (III.)

Pelecocera tricincta Meigen, 1822 - Tóth

1985, 1998 (II.)

Pipiza austriaca Meigen, 1822 - Tóth 1992 (II.)

Pipiza bimaculata Meigen, 1822 - Tóth

1992a, 1992b, 1995, 1998 (III.)

Pipiza fasciata (Meigen, 1822 ) - Tóth 1998 (II.)

Pipiza festiva Meigen, 1822 - Tóth 1992b,

1995,1998 (IV.)

Pipiza lugubris (Fabricius, 1775) - Tóth

1995, 1998 (III.)

Pipiza noctiluca (Linnaeus, 1758) - Tóth

1992a, 1992b, 1995, 1998 (IV.)

Pipizella annulata (Macquart, 1829) - Tóth 1995, 1998 (III.)

Pipizella divicoi (Goeldlin de Tiefenau, 1974) - Tóth 1995, 1998 (III.)

Pipizella maculipennis (Meigen, 1822) - Tóth

1992a, 1992b, 1995, 1998 (IV.)

Pipizella viduata (Linnaeus, 1758) - Szilády

1941, Tóth 1978, 1985, 1992a, 1992b, 1995, $1998(\mathrm{~V}$.

Pipizella virens (Fabricius, 1805) - Tóth $1978,1985,1992 \mathrm{a}, 1992 \mathrm{~b}, 1995,1998$ (IV.)

Pipizella zeneggenensis (Goeldlin de Tiefenau, 1974) - Tóth 1992b (I.)

Platycheirus albimanus (Fabricius, 1781) -

Tóth 1992a, 1992b, 1995, 1998 (IV.)

Platycheirus angustatus (Zetterstedt, 1843) -

Tóth 1985, 1992a, 1992b, 1995, 1998 (IV.)

Platycheirus clypeatus (Meigen, 1822) -

Thalhammer 1899, Tóth 1978, 1985, 1992a,

1992b, 1995, 1998 (V.)

Platycheirus discimanus (Loew, 1871) - Tóth 1992 b (I.)

Platycheirus fulviventris (Macquart, 1829) Thalhammer 1899, Tóth 1985, 1992a, 1992b, 1995, 1998 (IV.)

Platycheirus peltatus (Meigen, 1822) - Tóth 1985, 1995, 1998 (IV.)
Platycheirus scutatus (Meigen, 1822) - Tóth 1992b, 1995, 1998 (IV.)

Psarus abdominalis (Fabricius, 1794) - Tóth 1992b (11.)

Pyrophaena rosarum (Fabricius, 1787) - Tóth 1978, 1985, 1992b, 1995, 1998 (IV.)

Rhingia campestris Meigen, 1822 - Tóth 1992a, 1995, 1998 (III.)

Rhingia rostrata (Linnaeus, 1758) - Tóth 1998 (II.)

Scaeva pyrastri (Linnaeus, 1758) - Tóth 1978, 1985, 1992a, 1992b, 1995, 1998 (V.)

Scaeva selenitica (Meigen, 1822) - Tóth 1978, 1985, 1992a, 1992b, 1995, 1998 (IV.)

Spaerophoria hatava Goeldlin de Tiefenau, 1974 - Tóth 1992a, 1992b, 1998 (III.)

Sphaterophoria loesvi Zetterstedt, 1843 - Tóth 1998 (I.)

Sphaerophoria menthastri (Linnaeus, 1758) Tóth 1992b, 1995, 1998 (III.)

Sphaerophoria rueppelli (Wiedemann, 1830) Thalhammer 1899, Tóth 1978, 1985, 1995, 1998 (IV.)

Sphaerophoria scripta (Linnaeus, 1758) - Tóth 1978, 1985, 1992a, 1992b, 1995, 1998 (V.)

Sphaerophoria taeniata (Meigen, 1822) Tóth 1985, 1992a, 1992b, 1995, 1998 (IV.)

Sphaterophoria virgata Goeldlin de Tiefenau, 1974 - Tóth 1992b (III.)

Spilomyia diophthalma (Linnaeus, 1758) Tóth 1978, 1985, 1992b, 1998 (I.)

Syritta pipiens (Linnaeus, 1758) - Tóth 1978, 1985, 1992a, 1992b, 1995, 1998 (V.)

Syrphus ribesii (Linnaeus, 1758) - Tóth 1978, 1985, 1992a, 1992b, 1995, 1998 (V.)

Sysphus torvus Osten Sacken, 1875 - Tóth 1978, 1985, 1992a, 1992b, 1995, 1998 (IV.)

Syrphus vitripennis Meigen, 1822 - Tóth 1978, 1985, 1992a, 1992b, 1995, 1998 (V.)

Temnostoma bombylans (Fabricius, 1805) Tóth 1992a, 1992b, 1995, 1998 (III.)

Temnostoma vespiforme (Linnaeus, 1758) Tóth 1992b (II.)

Trichopsomyia flavitarsis (Meigen, 1822) -

Tóth 1992a, 1992b (II.)

Triglyphus primus Loew, 1840 - Tóth 1992b, 1995, 1998 (III.)

Tropidia scita (Harris, 1780) - Tóth 1992b, 1995, 1998 (IV.)

Volucella bombylans (Linnaeus, 1758) - Tóth 1992b, 1995, 1998 (IV.)

Volucella inanis (Linnaeus, 1758) - Tóth 1985, 1992a, 1995, 1998 (IV.)

Volucella inflata (Fabricius, 1794) - Tóth $1992 \mathrm{a}, 1992 \mathrm{~b}, 1995,1998$ (III.) 
Volucella pellucens (Linnaeus, 1758) - Tóth 1978, 1985, 1992a, 1992b, 1995, 1998 (IV.)

Volucella zonaria (Poda, 1761) - Tóth 1992a, 1992b, 1995, 1998 (IV.)

Xanthandrus comtus (Harris, 1780) - Tóth $1992 \mathrm{~b}, 1995,1998$ (III.)

Xanthogramma dives (Rondani, 1857) - Tóth 1995, 1998 (II.)

Xanthogramma festivum (Linnaeus, 1758) . Tóth 1978, 1985, 1992a, 1992b, 1995, 1998 (IV.)

Xanthogramma laetum (Fabricius, 1794) -
Tóth 1992a, 1992b, 1998(II.)

Xanthogramma pedisseguum (Harris, 1776) Tóth 1978, 1985, 1992a, 1992b, 1995, 1998 (IV.)

Xylota florum (Fabricius, 1805) - Tóth 1992a, 1992b (III.)

Xylota segnis (Linnaeus, 1758) - Tóth 1978 , 1985, 1992a, 1992b, 1995, 1998 (IV.)

Xylota sylvarum (Linnaeus, 1758) - Tóth 1992b, 1995, 1998 (III.)

Xylota xanthocnema Collin, 1939 - Tóth 1995, 1998 (III.)

\section{Irodalom}

DelY-DrASKovirs Á., 1972: Systematische und ökologische Untersuchungen an denin Ungarn als Schädlinge der Hutpilze auftretenden Fliegen, I. Limoniidae, Syrphidae, Platypezidae, Chloropidae (Diptera). - Acta Zool. Hung., 18: 7-21.

SzILÁDY Z., 1941: Diptera-kutatás a Balaton környékén - Magyar Biol. Kut. Munk. 13: 259-267. Thalhammer J., 1899: Ordo. Diptera. - In: A Magyar Birodalom Állatvilága. Fauna Regni Hung. p. 76.

TótH S., 1978: A Barcsi Ósborókás zengőlégy faunája (Diptera: Syrphidae) - Dunántúli Dolg. Term. tud. Sorozat 1: 127-138.

TớrH S., 1985: A Barcsi Borókás zengólégy faunája (Diptera: Syrphidae), II. - Dunántúli Dolg. Term. tud. Sorozat 5: 151-162.

TótH S., 1992a: Adatok a Zselic zengőlégy faunájához (Diptera: Syrphidae) - Somogyi Múz. Közlem., 9: 307-319.

TóTH S., 1992b: A Boronka-melléki Tájvédelmi Körzet zengólégy faunája (Diptera: Syrphidae) Dunántúli Dolg. Term. tud. Sorozat 7: 289-313.

TóTH S., 1995: A Dráva mente zengólégy faunájának alapvetése (Diptera: Syrphidae) - Dunántúli Dolg. Term. tud. Sorozat 8: 173-187.

TớTH S., 1998: A Duna-Dráva Nemzeti Park Dráva menti területének zengólégy faunája (Diptera: Syrphidae) - Dunántúli Dolg. Term. tud. Sorozat 9: 359-419. 


\section{Checklist of hover-flies of Somogy county (Diptera: Syrphidae)}

\section{SÁNDOR TÓTH}

The hover-fly fauna of Hungary is quite well known. Nowadays exactly 350 species are recorded from the country and 20 or 30 more species are expected to be found in the future. Due to the different faunistical research programs in Somogy county, the hover-fly fauna is considered to be well investigated. The hover-flies of Duna-Dráva National Park and the Boronka-melléki Landscape Protection Area are especially well known. According to the available data, the currently known fauna of the hover-flies in the county comprises 226 species, representing the $65 \%$ of the fauna of the country. The fauna is rich in rare and valuable elements. 17 of these sporadically occurring taxa are worth mentioning: Brachyopa bicolor (Fallén, 1817), Brachyopa insensilis Collin, 1939, Cheilosia lenis (Becker, 1894), Cheilosia schnabli (Becker, 1894), Criorhina ranunculi (Panzer, 1804), Eumerus flavitarsis Zetterstedt, 1843, Eumerus grandis Meigen, 1822, Eumerus ovatus Loew, 1848, Eumerus sabulonum (Fallén, 1817), Eumerus tarsalis Loew, 1848, Ferdinandea ruficornis (Fabricius, 1775), Orthonevra geniculata (Meigen, 1830), Orthonevra incisa (Loew, 1843), Parasyrphus macularis (Zetterstedt, 1843), Pipizella zeneggenensis (Goeldlin, 1974), Platycheirus discimanus (Loew, 1871), Sphaerophoria loewi Zetterstedt, 1843.

Author's address:

Dr. Sándor TóTH

H-8420 Zirc

Széchenyi u. 2.

HUNGARY 